Revista IBERC

v. 4 , n. 1, p. 19-34, jan./abr. 2021

www.responsabilidadecivil.org/revista-iberc

DOI: https://doi.org/10.37963/iberc.v3i2.140

\title{
A RESPONSABILIDADE CIVIL NO USO INDEVIDO DOS DADOS PESSOAIS
}

CIVIL LIABILITY IN IMPROPER USE OF PERSONAL DATA

Glenda Gonçalves Gondim i

RESUMO: A circulação de informações permeia a base da sociedade atual. Uma das fontes para sua formação refere-se aos dados, inclusive pessoais, que podem ser manipulados, transformados e até mesmo construídos. Para proteger a pessoa, a fim de que ela tenha um controle sobre o que é divulgado ou manipulado relativamente a ela, tem-se o direito sobre a proteção de dados pessoais. $O$ presente estudo versa sobre a responsabilidade civil decorrente da eventual conduta contrária a este direito. Para tanto, foi realizada revisão bibliográfica sobre o tema, bem como estudo da legislação brasileira, com ênfase para a Lei n. ${ }^{\circ} 13.709$, de 14 de agosto de 2018, que adota a responsabilização daquele que utilize indevidamente os dados de um indivíduo, com a consequente condenação a reparação do dano advindo desta conduta, cujo valor deve ser suficiente para evitar novos dados.

Palavras-chave: responsabilidade civil; dados; dano; reparação.

\begin{abstract}
The amount of information is the foundation of today's society. One of the sources for its formation refers to the data, including personal, that can be manipulated, transformed and even constructed. To protect the person, in order to control what is being disclosed or manipulated in relation to him, there is the entitlement to the protection of personal data. This study deals with civil liability arising from any conduct contrary to this right. Therefore, literature review on the subject was held as well as a study of Brazilian law, with particular emphasis on the Brazilian Act no. 13.709 of 14 August 2018, that adopt the responsibility of those who misuse the data of an individual, with the consequent condemnation to repair the damage arising from this conduct, for the repair, the value must be enough in order to prevent further damage.
\end{abstract}

Keywords: civil liability; data; damage; indemnity.

SUMÁRIO: Introdução. 1. A sociedade de informação e a tutela jurídica dos dados pessoais. 2. A responsabilidade civil pelo uso indevido de dados pessoais. 3. O dano a ser reparado. 4. Considerações finais. Referências bibliográficas.

\footnotetext{
i Doutora em Direito das Relações Sociais pela Universidade Federal do Paraná (2015). Mestre em Direito das Relações Sociais pela Universidade Federal do Paraná (2010). Pesquisadora do Grupo de Estudos de Direito Civil do Programa de Pós-Graduação em Direito Civil da Universidade Federal do Paraná - Virada de Copérnico (desde 2008). Especialista em Direito Empresarial pela Universidade Positivo (2004). Especialista em Responsabilidade Civil e Direito do Consumidor pela Faculdade de Direito de Curitiba (2001). Bacharel em Direito pela Faculdade de Direito de Curitiba (2000). Professora de Direito Civil da Universidade Positivo, onde leciona as disciplinas de Teoria Geral, Direito das Obrigações, Contratos, Responsabilidade Civil, Família e Sucessões. Integrante do Núcleo Docente Estruturante (NDE) do curso de Direito da Universidade Positivo. Professora convidada dos cursos de especialização em 'Direito Civil e Processo Civil' e 'Direito Médico' do Centro Universitário Curitiba (Unicuritiba). Autora do livro "Reparação civil na teoria da perda de uma chance" e autora de artigos jurídicos no tema de Direito Civil. Advogada militante na área cível desde 2001. E-mail: glendagondim@hotmail.com. ORCID https://orcid.org/0000-0002-5952-3143
} 


\section{INTRODUÇÃO}

A utilização de dados pessoais, cada vez mais comum na sociedade da informação, fez com que a sociedade e o próprio direito virassem os seus olhos para o tema, a fim de que se pudesse formular devida proteção jurídica. Surgiu, assim, o denominado direito sobre a proteção dos dados.

Trata-se de um direito considerado como fundamental, cujas respostas jurídicas para a sua ofensa podem ser a responsabilização administrativa, penal e civil do agente. No presente estudo, avalia-se a responsabilidade na seara cível.

O objetivo é estudar a aplicação da responsabilidade civil, a partir dos seus pressupostos, com o recorte específico da antijuridicidade e do dano. Assim, analisa-se a omissão legislativa da Lei n. ${ }^{\circ}$ 13.709, de 14 de agosto de 2018 (LGPD), ao não mencionar, de forma proposital ou não, se a responsabilização do agente é objetiva ou subjetiva, bem como o dano a ser reparado. Optou-se pela revisão bibliográfica e legislativa, através do método crítico-descritivo.

Parte-se do estudo da sociedade de informação e da tutela jurídica dos dados pessoais, para, então, se proceder à análise das disposições apresentadas na Lei Geral de Proteção de Dados (Lei n. ${ }^{\circ}$ 13.709/2018). Posteriormente, verifica-se a possibilidade da responsabilização e qual a sua natureza, diante da classificação (em subjetiva e objetiva) e a omissão legislativa. Por fim, avalia-se o dano decorrente e a sua reparação, especialmente diante dos valores em discussão e da necessidade de se evitar futuras lesões análogas.

\section{A SOCIEDADE DE INFORMAÇÃO E A TUTELA JURÍDICA DOS DADOS PESSOAIS}

A informação criou uma sociedade com modelo capitalista de produção próprio1, cujos primeiros sinais emergem com a tecnologia digital, que permitiu a rápida transmissão das informações a nível mundial ${ }^{2}$. E essa passou a ser a fonte dessa sociedade, na qual o seu possuidor ascende a uma relevante posição social, pois ela se sobrepõe aos bens de produção anteriormente existentes ${ }^{3}$. E vai além, pois importa não apenas a posse ou concentração, mas também a destinação e geração de novos conhecimentos ${ }^{4}$, em razão de sua manipulação.

As possibilidades de tratamento e divulgação da informação instigaram a proteção jurídica sobre o tema que, inicialmente, versava sobre o direito de acesso e que, atualmente, trata da possibilidade de proteção jurídica do que é analisado como patrimônio informativo ${ }^{5}$. O objetivo

\footnotetext{
${ }^{1}$ CASTELLS, Manuel. A sociedade em rede. A era da informação: economia, sociedade e cultura. Tradução de Roneide Venancio Majer. 20. ed., rev. e ampl. v. 1. São Paulo: Paz e Terra, 2019, p. 72.

2 PINHEIRO, Patrícia Peck. Direito digital. 6. ed., rev., atual. e ampl. São Paulo: Saraiva, 2016, p. 52.

3 PINHEIRO, Patrícia Peck. Direito digital. 6. ed., rev., atual. e ampl. São Paulo: Saraiva, 2016, p. 89.

${ }^{4}$ CASTELLS, Manuel. A sociedade em rede. A era da informação: economia, sociedade e cultura. Tradução de Roneide Venancio Majer. 20. ed., rev. e ampl. v. 1. São Paulo: Paz e Terra, 2019, p. 88.

${ }^{5}$ RODOTÀ, Stefano. A vida na sociedade de vigilância: a privacidade hoje. Tradução de Danilo Doneda e Luciana Cabral Doneda. Organização, seleção e apresentação de Maria Celina Bodin de Moraes. Rio de Janeiro: Renovar, 2008, p. 44.
} 
é que a proteção alcance não apenas a informação em si, mas o que pode ser considerado como sua matéria prima, os dados ${ }^{6}$.

Dados pessoais (que dizem respeito ao nome, endereço, titulação, foto, parentesco, enfim, tudo que possa se referir a um indivíduo) são as "pré-informações" sobre alguém. Ao serem manipulados, alcançam algo além da representação contida no "dado primário", chegando ao limiar da cognição ${ }^{7}$. Por isso, diz-se que um dado poderá gerar novos dados.

Com métodos, algoritmos e técnicas de processamento advindos da internet, uma maior quantidade de dados passou a ser processada em menos tempo e resultados mais valiosos passaram a ser obtidos. ${ }^{8}$ Resultados que podem ser utilizados para diversos fins, seja para traçar um perfil como consumidor de produtos e serviços, a fim de encaminhar informações publicitárias ${ }^{9}$; para propaganda política ${ }^{10}$, podendo "levar à total modificação do cenário econômico, político e social"11; para concessão de crédito; e para selecionar candidatos em processos seletivos na área de recursos humanos. Estes são apenas alguns exemplos das possíveis consequências que podem ser pensadas.

Por isso, diz-se que os dados reunidos e manipulados contêm informações sobre a pessoa e, portanto, são uma extensão desta e, diante de todas as interferências na vida de cada indivíduo, são merecedores de tutela jurídica, da qual decorre o que se denominou como direito à proteção sobre dados pessoais.

Um direito autônomo, uma vez que se trata de uma problemática complexa, que ultrapassa a esfera do direito à privacidade ${ }^{12}$, pois atinge outros direitos da personalidade e quiçá a própria democracia ${ }^{13}$.

Também. um direito inserido na categoria dos direitos fundamentais ${ }^{14}$. Inclusive, no Brasil, há Proposta de Emenda Constitucional com o objetivo de legislar como tal, para inserção deste direito no art. $5^{\circ}$, inciso XII-A, e no art. 22, ambos da Constituição Federal (Proposta de Emenda Constitucional n. ${ }^{\circ} 17$ de $\left.2019^{15}\right)$. Isto porque, entende-se que a atual redação que versa

\footnotetext{
6 “(...) O dado é o estado primitivo da informação, pois não é algo per se que acresce conhecimento. Dados são simplesmente fatos brutos que, quando processados e organizados, se convertem em algo inteligível, podendo ser deles extraída uma informação". (BIONI, Bruno Ricardo. Proteção de dados pessoais: a função e os limites do consentimento. Rio de Janeiro: Forense, 2019, p. 36)

${ }^{7}$ DONEDA, Danilo. Da privacidade à proteção de dados pessoais. Rio de Janeiro: Renovar, 2006.

${ }^{8}$ DONEDA, Danilo. Da privacidade à proteção de dados pessoais. Rio de Janeiro: Renovar, 2006, p. 12.

${ }^{9} \mathrm{BIONI}$, Bruno Ricardo. Proteção de dados pessoais: a função e os limites do consentimento. Rio de Janeiro: Forense, 2019, p. 19.

${ }^{10}$ RODOTÀ, Stefano. Obra citada, p. 126.

${ }^{11}$ FRAZÃO, Ana. Fundamentos da proteção dos dados pessoais - Noções introdutórias para a compreensão da importância da Lei Geral da Proteção de Dados. In: FRAZÃO, Ana; TEPEDINO, Gustavo; OLIVA, Milena Donato (Coord.). Lei Geral de Proteção de Dados Pessoais e suas repercussões no Direito Brasileiro. São Paulo: Thomson Reuters Brasil, 2019, p. 23-52, p. 32.

${ }^{12}$ BIONI, Bruno Ricardo. Proteção de dados pessoais: a função e os limites do consentimento. Rio de Janeiro: Forense, 2019, p. 98.

${ }^{13}$ FRAZÃO, Ana. Objetivos e alcance da Lei Geral de Proteção de Dados In: FRAZÃO, Ana; TEPEDINO, Gustavo; OLIVA, Milena Donato (Coord.). Lei Geral de Proteção de Dados Pessoais e suas repercussões no Direito Brasileiro. São Paulo: Thomson Reuters Brasil, 2019, p. 99-129, p. 100.

${ }^{14}$ LUÑO, Antonio E. Pérez. Informática y libertad. Comentario ao articulo 18.4 de la Constitucion. Revista de Estudios Politicos, n. 24, nov. 1981, p. 38.

${ }^{15}$ BRASIL. Proposta de Emenda Constitucional n. ${ }^{\circ}$ 17/2019. Disponível em https://www25.senado.leg.br/ web/atividade/materias/-/materia/135594. Acesso em: 12 set. 2020.
} 
sobre dados (art. $5^{\circ}, \mathrm{XIII}$, da CF) estaria restrita ao sigilo e, portanto, não abrangeria todas as situações que devem ser tuteladas.

Este é o mesmo entendimento previsto na Carta de Direitos Fundamentais da União Europeia $^{16}$, consequentemente, no Regulamento Geral de Proteção de Dados ${ }^{17}$, bem como dos Padrões de Proteção de Dados dos Estados Ibero-Americanos, em que a proteção aos dados de pessoas físicas é considerada como direito fundamental, "reconhecida como categoria máxima na maioria das Constituições Políticas dos Estados Ibero-Americanos"18. As duas regulamentações são citadas a título de exemplificação, a fim de demonstrar a tendência mundial sobre o tema.

No Brasil, há o entendimento de que se trata de um direito autônomo e fundamental, pois, apesar de estar posto de forma transversal e por ser relacionado aos direitos à privacidade e à intimidade, por exemplo ${ }^{19}$, o seu objetivo é prezar pelo titular dos dados, com base na autodeterminação informativa, como forma de manter a titularidade. Inclusive, na Lei Geral de Proteção de Dados Pessoais (Lei n. ${ }^{\circ} 13.709$, de 14 de agosto de 2018), comumente denominada como LGPD, a proteção de dados tem como fundamentos outros direitos e, por isso, não seria por eles abrangida, são eles: a privacidade, a autodeterminação informativa, a intimidade, os direitos humanos e a dignidade, dentre outros (art. $2^{\circ}$, da LGPD ${ }^{20}$ ).

A relação com os direitos citados permite relacionar a proteção jurídica sobre dados à noção contemporânea de titularidade. Isso significa dizer que o indivíduo tem poder sobre os seus

\footnotetext{
${ }^{16}$ Artigo 8.o Protecção de dados pessoais 1. Todas as pessoas têm direito à protecção dos dados de carácter pessoal que lhes digam respeito. 2. Esses dados devem ser objecto de um tratamento leal, para fins específicos e com o consentimento da pessoa interessada ou com outro fundamento legítimo previsto por lei. Todas as pessoas têm o direito de aceder aos dados coligidos que lhes digam respeito e de obter a respectiva rectificação. 3. O cumprimento destas regras fica sujeito a fiscalização por parte de uma autoridade independente. (UNIÃO EUROPEIA. Carta dos Direitos Fundamentais da União Europeia (CDFUE). 07 de dezembro de 2000. Disponível em https://www.cnpd.pt/home/legis/internacional/CARTAFUNDAMENTAL.pdf Acesso em: 10 ago. 2020).

17 Ao iniciar os considerados do Regulamento, tem-se "Considerando o seguinte: (1) A proteção das pessoas singulares relativamente ao tratamento de dados pessoais é um direito fundamental. $\mathrm{O}$ artigo 8.0, n.o 1, da Carta dos Direitos Fundamentais da União Europeia ("Carta») e o artigo 16.o, n.o 1, do Tratado sobre o Funcionamento da União Europeia (TFUE) estabelecem que todas as pessoas têm direito à proteção dos dados de caráter pessoal que Ihes digam respeito." (Regulamento Geral de Proteção de Dados). (UNIÃO EUROPEIA. Regulamento n. ${ }^{\circ} 2016 / 679$ do Parlamento Europeu e do Conselho de 27 de abril de 2016. Regulamento Geral de Proteção de Dados. Disponível em https://eur-lex.europa.eu/legalcontent/PT/TXT/HTML/?uri=CELEX:32016R0679\&from=EN. Acesso em: 03 maio 2020.)

18 SECRETARIA GERAL IBERO AMERICANA. RIPD 2020. Rede Ibero Americana de Proteção de Dados. Padrões de Proteção de Dados dos Estados Ibero-Americanos. Disponível em https://www.argentina.gob.ar/sites/default/files/pt_br_estandares_iberoamericanos_de_proteccion_de_datos .pdf. Acesso em: 03 mar. 2020.

19 "Consequentemente, as discussões sobre os objetivos da proteção dos dados pessoais, longe de se afastarem a conexão dessa tutela com a proteção da intimidade e do direito de ser deixado só, apenas ampliam a problemática e a tornam mais complexa, na medida em que a conectam com importantes direitos e garantias fundamentais da democracia." (FRAZÃO, Ana. Objetivos e alcance da Lei Geral de Proteção de Dados In: FRAZÃO, Ana; TEPEDINO, Gustavo; OLIVA, Milena Donato (Coord.). Lei Geral de Proteção de Dados Pessoais e suas repercussões no Direito Brasileiro. São Paulo: Thomson Reuters Brasil, 2019, p. 99129, p. 110).

${ }^{20}$ Art. $2^{\circ} \mathrm{A}$ disciplina da proteção de dados pessoais tem como fundamentos: I - o respeito à privacidade; II a autodeterminação informativa; III - a liberdade de expressão, de informação, de comunicação e de opinião; IV - a inviolabilidade da intimidade, da honra e da imagem; V - o desenvolvimento econômico e tecnológico e a inovação; VI - a livre iniciativa, a livre concorrência e a defesa do consumidor; e VII - os direitos humanos, o livre desenvolvimento da personalidade, a dignidade e o exercício da cidadania pelas pessoas naturais. (BRASIL, Lei n. ${ }^{\circ} 13.709$, de 14 de agosto de 2018. Lei Geral de Proteção de Dados. Disponível em: http://www.planalto.gov.br/ccivil_03/_ato2015-2018/2018/lei/L13709.htm. Acesso em: 20 set. 2020.).
} 
dados e, por conseguinte, pode definir a destinação destes, assim como interromper o fluxo das informações sobre si ou requerer descrição das informações que lhe dizem respeito. É a sequência mencionada por Rodotà sobre "pessoa-informação-circulação-controle"21. Por isso a titularidade é entendida como o controle sobre as suas próprias informações ${ }^{22}$.

Ao titular dos dados é atribuído "o direito de deles dispor e o poder de controlá-los 23". Trata-se do dever-direito de informação ${ }^{24}$, o qual pode ser representado por um termo de consentimento informado, no sentido de que "o titular do bem tem de ter ao seu dispor as informações necessárias e suficientes para avaliar corretamente a situação e a forma como seus dados serão tratados" 25 para possibilitar a compreensão sobre quais são os dados que serão coletados, a finalidade desta coleta, como serão manipulados (se o forem) e, em caso de eventual compartilhamento, o conhecimento sobre quem poderá obter essa informação e para qual finalidade.

São a coleta, o armazenamento e, sobretudo, o compartilhamento que circundam as maiores preocupações para com o respeito ao titular desses dados. Porque quando alguém coleta um dado pessoal, sem a autorização do seu titular, pode obter novas informações sobre este indivíduo que perde, portanto, a possibilidade de controle. A partir destas ideias, que não são as únicas, mas as que perpassam este estudo, passa-se a analisar a responsabilização em caso de lesão a este direito.

\section{A RESPONSABILIDADE CIVIL PELO USO INDEVIDO DE DADOS PESSOAIS}

A existência do direito a proteção sobre os dados pessoais importa dizer que nenhuma informação pode ser obtida à revelia do seu titular, desde a sua coleta, alteração de finalidade ou compartilhamento e, se assim ocorrer, entende-se como algo contrário ao ordenamento jurídico, e, por isso, indevido.

Assim, toda e qualquer utilização indevida, como a obtenção sem o devido controle do titular, será considerada contrária ao ordenamento jurídico (acaso não exista exceção legal que

${ }^{21}$ RODOTÀ, Stefano. A vida na sociedade de vigilância: a privacidade hoje. Tradução de Danilo Doneda e Luciana Cabral Doneda. Organização, seleção e apresentação de Maria Celina Bodin de Moraes. Rio de Janeiro: Renovar, 2008, p. 93.

22 MAIA, Roberta Mauro Medina. A titularidade de dados pessoais prevista no art. 17 da LGPD: direito real ou pessoal? In: FRAZÃO, Ana; TEPEDINO, Gustavo; OLIVA, Milena Donato (Coord.). Lei Geral de Proteção de Dados Pessoais e suas repercussões no Direito Brasileiro. São Paulo: Thomson Reuters Brasil, 2019, p. 147.

${ }^{23}$ MAIA, Roberta Mauro Medina. A titularidade de dados pessoais prevista no art. 17 da LGPD: direito real ou pessoal? In: FRAZÃO, Ana; TEPEDINO, Gustavo; OLIVA, Milena Donato (Coord.). Lei Geral de Proteção de Dados Pessoais e suas repercussões no Direito Brasileiro. São Paulo: Thomson Reuters Brasil, 2019, p. 150.

${ }^{24}$ BIONI, Bruno Ricardo. Proteção de dados pessoais: a função e os limites do consentimento. Rio de Janeiro: Forense, 2019, p. 195.

25 TEPEDINO, Gustavo. TEFFÉ, Chiara Spadaccini. Consentimento e proteção de dados pessoais na LGPD. In: FRAZÃO, Ana; TEPEDINO, Gustavo; OLIVA, Milena Donato (Coord.). Lei Geral de Proteção de Dados Pessoais e suas repercussões no Direito Brasileiro. São Paulo: Thomson Reuters Brasil, 2019, p. 287-322, p. 301. 
previamente a regulamente) e poderá ocasionar a responsabilização civil, uma vez que será considerada como ato antijurídico (no seu sentido lato). ${ }^{26}$

Algo já reconhecido pelos Tribunais brasileiros, como no julgamento proferido pelo Superior Tribunal de Justiça no Recurso Especial n. ${ }^{1}$ 1.758.799/MG ${ }^{27}$, antes da vigência da LGPD. Neste caso, discutiu-se o armazenamento e a comercialização indevida de informações pessoais. O autor da ação processou a empresa que disponibilizava informações pessoais sobre ele e diversos indivíduos em um site. Neste ambiente virtual, era possível ter acesso ao endereço de pessoas que foram cadastradas pela empresa demandada, informações sobre quem são os vizinhos dele, os nomes de possíveis parentes, pessoas residentes no mesmo endereço, dentre outros. Os cadastros eram feitos e alimentados com informações obtidas no comércio em geral. Isto é, quando o titular realizava compras ou serviços na Rede Mundial de Computadores, ao informar o seu endereço ou seu nome, a empresa ré coletava os dados e criava os cadastros, os quais eram alterados e completados com novas pesquisas em redes sociais e outras negociações realizadas por este titular. O objetivo era manter as informações atualizadas.

Como o titular não havia autorizado e, muitas vezes, sequer tinha conhecimento de que suas informações eram disponibilizadas pelo site da demandada, requereu sua condenação na obrigação de fazer, para excluir os dados, assim como condená-la ao pagamento de indenização por danos morais. O Superior Tribunal de Justiça entendeu pela condenação da empresa, tanto para a exclusão dos dados do autor de seus cadastros, quanto para o pagamento de indenização. Isso porque entendeu-se que a não informação ao consumidor sobre o tratamento dos dados (coleta, armazenamento e compartilhamento) enseja a indenização (por danos in re ipsa) e o dever de cessar a ofensa aos direitos da personalidade.

Com o advento da Lei Geral de Proteção de Dados Pessoais no Brasil, essa responsabilidade fica mais clara, tendo em vista que a legislação prevê a responsabilização do controlador (aquele que detém o poder de decisões sobre o tratamento de dados) e do operador (quem realiza o tratamento de dados em nome do controlador), ao determinar que este será responsabilizado por atos ilegais (contrários ao direito) e pelo tratamento de dados contrário à lei28, como o caso acima citado, em que não existia autorização ou conhecimento do titular sobre os dados que eram coletados e comercializados.

A antijuridicidade, no seu sentido lato, deve ser interpretada para além do que dispõe a LGPD. É que a legislação apresenta uma redação que não seria a mais apropriada para a

\footnotetext{
${ }^{26}$ Sobre tema: VENTURI, Thaís Goveia Pascoaloto. Responsabilidade civil preventiva: a proteção contra a violação dos direitos e a tutela inibitória material. São Paulo: Malheiros, 2014.

${ }^{27}$ BRASIL. Superior Tribunal de Justiça. Recurso Especial n. ${ }^{\circ}$.758.799/MG (2017/0006521-9). Relatora Ministra Nancy Andrighi. Terceira Turma. Julgado em 12/11/2019, DJe 19/11/2019. Disponível em: https://ww2.stj.jus.br/websecstj/cgi/revista/REJ.cgi/lTA?seq=1888267\&tipo=0\&nreg=201700065219\&SeqCg rmaSessao=\&CodOrgaoJgdr=\&dt=20191119\&formato=PDF\&salvar=false. Acesso em: 17 dez. 2019.

28 "Art. 42. O controlador ou o operador que, em razão do exercício de atividade de tratamento de dados pessoais, causar a outrem dano patrimonial, moral, individual ou coletivo, em violação à legislação de proteção de dados pessoais, é obrigado a repará-lo." (BRASIL, Lei n. ${ }^{\circ} 13.709$, de 14 de agosto de 2018. Lei Geral de Proteção de Dados. Disponível em: http://www.planalto.gov.br/ccivil_03/_ato20152018/2018/lei/L13709.htm. Acesso em: 20 set. 2020.).
} 
regulamentação do tema. O art. 44 da LGPD $^{29}$ elenca algumas hipóteses de responsabilização sobre o que seria entendido como tratamento de dados irregular, mas as situações nele previstas devem ser interpretadas como meramente exemplificativas e não exaustivas, para evitar um conflito com possíveis danos decorrentes de outros possíveis casos. Afinal, deve-se primar pela proteção da pessoa e, por consequência, salvaguardá-la de todas as possíveis lesões que lhe ocasionem dano.

Outro ponto que merece atenção para a análise sobre o tema e como restou previsto na LGPD, é que o legislador se omitiu em um relevante ponto para a aplicação prática da responsabilidade, que se trata da avaliação sobre se será uma responsabilidade subjetiva (com a necessidade de comprovação de culpa) ou objetiva (independentemente de culpa).

Ao se omitir, a primeira conclusão é de que estaria inserida na regra geral da responsabilização subjetiva, uma vez que, para afastar o pressuposto da culpa, a conduta deve estar prevista em lei ou importar em atividade de risco (art. 927 do Código Civil ${ }^{30}$ ). Mas, há divergência sobre o tema.

Para os que defendem a necessidade de comprovação de culpa e, portanto, a aplicação da regra geral da responsabilidade subjetiva, o embasamento decorre dos deveres a serem cumpridos pelos agentes (controlador e operador) e que estão previstos na legislação. Neste entendimento, não seria lógica a existência destes deveres se não fosse para avaliação do pressuposto da culpa ${ }^{31}$. Ainda, entendem que, ao dispor sobre comportamentos que devam ser adotados para o tratamento de dados, "[a] LGPD indicaria qual é o padrão de conduta socialmente esperado - o standard - que deve ser seguido pelos agentes de tratamento de dados"32. E comportamentos standards são considerados fundamentos básicos para análise da culpa.

\footnotetext{
${ }^{29}$ Art. 44. O tratamento de dados pessoais será irregular quando deixar de observar a legislação ou quando não fornecer a segurança que o titular dele pode esperar, consideradas as circunstâncias relevantes, entre as quais: I - o modo pelo qual é realizado; II - o resultado e os riscos que razoavelmente dele se esperam; III - as técnicas de tratamento de dados pessoais disponíveis à época em que foi realizado. Parágrafo único. Responde pelos danos decorrentes da violação da segurança dos dados o controlador ou o operador que, ao deixar de adotar as medidas de segurança previstas no art. 46 desta Lei, der causa ao dano. (BRASIL, Lei n. ${ }^{\circ}$ 13.709, de 14 de agosto de 2018. Lei Geral de Proteção de Dados. Disponível em: http://www.planalto.gov.br/ccivil_03/_ato2015-2018/2018/lei/L13709.htm. Acesso em: 20 set. 2020.).

30 "Art. 927. Aquele que, por ato ilícito (arts. 186 e 187), causar dano a outrem, fica obrigado a repará-lo.

Parágrafo único. Haverá obrigação de reparar o dano, independentemente de culpa, nos casos especificados em lei, ou quando a atividade normalmente desenvolvida pelo autor do dano implicar, por sua natureza, risco

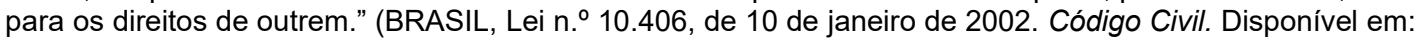
http://www.planalto.gov.br/ccivil_03/leis/2002//10406.htm. Acesso em: 03 maio 2020.)

31 "Assim, não faz muito sentido- nem do ponto de vista lógico, nem do jurídico - o legislador criar uma série de deveres de cuidado se não for para implantar um regime de responsabilidade subjetiva. Se o que se pretende é responsabilizar os agentes, independentemente de culpa de fato, não faz sentido criar deveres a serem seguidos, tampouco responsabilizá-los quando tiverem cumprido perfeitamente todos esses deveres. A lógica da responsabilidade objetiva é outra, completamente diferente: não cabe discutir cumprimento de deveres, porque, quando se discute cumprimento de deveres, o que no fundo está sendo analisado é se o agente atuou ou não com culpa". (GUEDES, Gisela Sampaio da Cruz. MEIRELLES, Rose Melo Vencelau. Término do tratamento de dados. In: FRAZÃO, Ana; TEPEDINO, Gustavo; OLIVA, Milena Donato (Coord.). Lei Geral de Proteção de Dados Pessoais e suas repercussões no Direito Brasileiro. São Paulo: Thomson Reuters Brasil, 2019, p. 219-241, p. 231).

32 GUEDES, Gisela Sampaio da Cruz. MEIRELLES, Rose Melo Vencelau. Término do tratamento de dados. In: FRAZÃO, Ana; TEPEDINO, Gustavo; OLIVA, Milena Donato (Coord.). Lei Geral de Proteção de Dados Pessoais e suas repercussões no Direito Brasileiro. São Paulo: Thomson Reuters Brasil, 2019, p. 219-241, p. 233.
} 
Há que se salientar que o próprio Código de Defesa do Consumidor, cujo alicerce é a responsabilidade objetiva, com exceção apenas para a responsabilidade dos profissionais liberais ${ }^{33}$, dispõe sobre deveres a serem seguidos pelos fornecedores e decorrentes da boa-fé objetiva, mas isso não afasta o fato de ser prescindível a análise da culpa para os casos de responsabilizações ${ }^{34}$ fundadas nesta legislação.

Merece destaque uma parte da doutrina que entende que a legislação que versa sobre dados apresenta uma nova modalidade de responsabilidade civil, qual seja uma "responsabilidade ativa" ou "proativa" ${ }^{35}$, eis que, além da exigência do cumprimento dos deveres legais, há a necessidade de comprovação de medidas para comprovar essa observância, bem como a demonstração da efetividade destas, com fulcro no disposto no art. $6^{\circ}, X$, da $\operatorname{LGPD}^{36}$, que conceitua a responsabilização e prestação de contas, a partir de uma conduta cônscia e proativa. Para esta corrente é exigível não apenas o cumprimento dos deveres legais, mas também, a adoção de "atitudes conscientes, diligentes e proativas por parte das empresas em relação à utilização dos dados pessoais"37.

E, por outro lado, parte da doutrina entende que o tratamento de dados (como um todo) é atividade de risco ${ }^{38}$. Assim, seria responsabilidade objetiva que prescinde da culpa, em razão da cláusula geral prevista no art. 927, parágrafo único, do Código Civil brasileiro ${ }^{39}$.

A inserção do risco como cláusula geral disposta pelo legislador brasileiro foi assim preceituada, exatamente, para possibilitar "pela atividade de interpretação e concreção judicial sua aplicação a novas situações ou riscos que venham a surgir ou se desenvolver com base nos avanços da ciência e da técnica"40.

33 "Art. 14. (...) $\S 4^{\circ} \mathrm{A}$ responsabilidade pessoal dos profissionais liberais será apurada mediante a verificação de culpa." (BRASIL, Lei n. ${ }^{\circ} 8.078$, de 11 de setembro de 1990. Código de Defesa do Consumidor. Disponível em http://www.planalto.gov.br/ccivil_03/leis//8078compilado.htm. Acesso em 03 de maio de 2020.).

${ }^{34}$ MULHOLLAND, Caitlin. A LGPD e o fundamento da responsabilidade civil dos agentes de tratamento de dados pessoais: culpa ou risco? Migalhas. Migalhas de responsabilidade civil. Disponível em https://www.migalhas.com.br/coluna/migalhas-de-responsabilidade-civil/329909/a-lgpd-e-o-fundamento-daresponsabilidade-civil-dos-agentes-de-tratamento-de-dados-pessoais--culpa-ou-risco. Acesso em 20 de julho de 2020.

35 MORAES, Maria Celina Bodin de. QUEIROZ, João Quinelato de. Autodeterminação informativa e responsabilização proativa: novos instrumentos de tutela da pessoa humana na LGPD. Proteção de Dados Pessoais: avanço tecnológico. Cadernos Adenauer. Ano XX (2019), n. ${ }^{\circ} 3$. Rio de Janeiro: Fundação Konrad Adenauer, outubro 2019, p. 129.

36 "Art. $6^{\circ}(\ldots) X$ - responsabilização e prestação de contas: demonstração, pelo agente, da adoção de medidas eficazes e capazes de comprovar a observância e o cumprimento das normas de proteção de dados pessoais e, inclusive, da eficácia dessas medidas." (BRASIL, Lei n. ${ }^{\circ} 13.709$, de 14 de agosto de 2018. Lei Geral de Proteção de Dados. Disponível em: http://www.planalto.gov.br/ccivil_03/_ato20152018/2018/lei/L13709.htm. Acesso em: 20 set. 2020.)

37 MORAES, Maria Celina Bodin de. QUEIROZ, João Quinelato de. Autodeterminação informativa e responsabilização proativa: novos instrumentos de tutela da pessoa humana na LGPD. Proteção de Dados Pessoais: avanço tecnológico. Cadernos Adenauer. Ano XX (2019), n. ${ }^{\circ}$. Rio de Janeiro: Fundação Konrad Adenauer, outubro 2019, p. 130.

38 DONEDA, Danilo. A proteção dos dados pessoais como um direito fundamental. Espaço Jurídico. Joaçaba, v. 12, n. 2. Jul/dez. 2011, p. 92.

39 "Art. 927 [...]. Parágrafo único. Haverá obrigação de reparar o dano, independentemente de culpa, nos casos especificados em lei, ou quando a atividade normalmente desenvolvida pelo autor do dano implicar, por sua natureza, risco para os direitos de outrem." (BRASIL, Lei n. ${ }^{\circ} 10.406$, de 10 de janeiro de 2002. Código Civil. Disponível em: http://www.planalto.gov.br/ccivil_03/leis/2002/l10406.htm. Acesso em: 03 maio 2020.)

40 MIRAGEM, Bruno. Direito civil: responsabilidade civil. São Paulo: Saraiva, 2015, p. 107. 
Em uma interpretação sistêmica, especialmente fundamentada no fato de que o pressuposto da culpa permanece como um filtro da reparação ${ }^{41}$, o que poderia ocasionar a ampla proteção da pessoa, a melhor interpretação tende a ser a responsabilidade objetiva. Corrobora esta interpretação, o fato de que para além do risco decorrente da atividade, a lesão eventualmente ocasionada afeta um direito fundamental da vítima ${ }^{42}$.

Por isso, pensando na pessoa e na interpretação sistêmica, a melhor conclusão seria pela responsabilidade objetiva do agente, não apenas pela tendência de objetivação, mas também porque a verificação da culpa, ainda que de forma objetiva, através da análise do descumprimento de deveres legais, pode impedir a reparação integral da vítima.

Analisada essa controvérsia instaurada na doutrina, apesar da ausência de unanimidade, o que não se discute é sobre a possibilidade de responsabilizar o agente que descumpre o direito sobre a proteção de dados. E, diante dessa premissa, passa-se a analisar o pressuposto dano.

\section{O DANO A SER REPARADO}

Analisada a possibilidade de aplicação da responsabilidade civil para os casos de uso indevido dos dados, estuda-se o dano ocasionado e como ocorrerá a sua reparação.

É sabido que este bem jurídico - o dado - pode ter conotação patrimonial para quem os utiliza e comercializa, mas, frequentemente, a sua apreciação não é mensurável para a vítima e, portanto, na maioria dos casos, estar-se-á diante de um dano extrapatrimonial/moral.

Esclarece-se que é possível uma lesão ao patrimônio da vítima para casos específicos, desde que reste comprovado que houve lesão a bens materiais. Os maiores exemplos disso são quando o uso indevido está relacionado com fraudes. Por exemplo, se uma empresa divulga indevidamente os dados de seus clientes e a pessoa que os acessa cria contas correntes em instituições financeiras em nome dessas pessoas, com obtenção de empréstimos. Além da possibilidade de responsabilizar a instituição financeira, ante a fraude em relação aos usos de dados pessoais, cuja responsabilidade é objetiva ${ }^{43}$, verificado $\mathrm{o}$ ato antijurídico praticado pela empresa que divulgou estes dados, essa também poderá ser responsabilizada.

Também há o caso julgado pelo Juizado Especial Cível de Rio Branco do Sul, Estado do Paraná, nos autos n. ${ }^{\circ}$ 0000007-20.2020.8.16.0147, no qual o autor pagou boleto emitido de forma

\footnotetext{
41 SCHREIBER, Anderson. Novos paradigmas da responsabilidade civil: da erosão dos filtros da reparação à diluição dos danos. São Paulo: Atlas, 2007, p. 35.

42 MULHOLLAND, Caitlin. A LGPD e o fundamento da responsabilidade civil dos agentes de tratamento de dados pessoais: culpa ou risco? Migalhas. Migalhas de responsabilidade civil. Disponível em https://www.migalhas.com.br/coluna/migalhas-de-responsabilidade-civil/329909/a-lgpd-e-o-fundamento-daresponsabilidade-civil-dos-agentes-de-tratamento-de-dados-pessoais--culpa-ou-risco. Acesso em 20 de julho de 2020.

${ }^{43}$ A responsabilidade objetiva das instituições financeiras em casos de fraudes está prevista na Súmula 479, do STJ, que dispõe: "As instituições financeiras respondem objetivamente pelos danos gerados por fortuito interno relativo a fraudes e delitos praticados por terceiros no âmbito de operações bancárias". (BRASIL. Superior Tribunal de Justiça. Súmula 479. Disponível em https://scon.stj.jus.br/SCON/sumanot/toc.jsp. Acesso em: 29 ago. 2020)
} 
fraudulenta e requereu a responsabilização da empresa financiadora pelos danos materiais e morais resultantes da cobrança posterior do valor e inscrição do seu nome no Serasa. Foi proferida sentença que condenou a financeira, visto que a emissão do boleto do fraudador só foi possível porque um terceiro teve acesso aos dados do contrato. Portanto, entendeu-se que a financeira possibilitou a fraude e esta foi condenada ao pagamento de danos materiais, em $R \$ 10.499,98$ (dez mil, quatrocentos e noventa e nove reais e noventa e oito centavos) e danos morais em $R \$$ $2.000,00$ (dois mil reais) ${ }^{44}$.

Nesses casos, hipotéticos ou reais, resta flagrante a possibilidade de danos materiais, além de danos morais. Todavia, na maioria dos casos, a utilização indevida lesa a extrapatrimonialidade, ou seja, algo imaterial sem o vínculo patrimonial para o ofendido ${ }^{45}$.

Desta forma, revela-se que não tendo impacto diretamente sobre o patrimônio da vítima (repita-se, usualmente), será considerado como dano extrapatrimonial/moral e, por isso, deverá ser reparado como tal. Consequentemente, há a dificuldade de reparação que Ihe é própria, uma vez que reparar patrimonialmente algo que não tem cunho patrimonial acarreta um problema de origem ${ }^{46}$ e de valoração $0^{47}$.

Para esta valoração não se pode olvidar do poder econômico dos dados para aquele que realizou indevidamente a sua utilização. E, assim, a compensação deste dano deve ser realizada a partir de dois pontos: a "[...] satisfação pecuniária em primeira linha contra o ofensor, mas secundariamente, de modo preventivo, também sobre o público"48.

Se reparar deve ser também prevenir ${ }^{49}$, o valor deve considerar um desestímulo ao ofensor, razão pela qual deve ser avaliado o valor econômico dos dados, ainda que presumidamente.

No caso mencionado anteriormente e julgado pelo Superior Tribunal de Justiça, a empresa que comercializava dados sem autorização dos seus titulares foi condenada ao pagamento de danos morais no valor de $\mathrm{R} \$ 8.000,00$ (oito mil reais) ${ }^{50}$. A fundamentação do arbitramento desta quantia é de que este valor cumpriria o objetivo de reparar e desestimular o ofensor.

44 PARANÁ. Tribunal de Justiça. Autos $n .^{\circ}$ 0000007-20.2020.8.16.0147. Disponível em https://projudi.tjpr.jus.br/projudi/. Acesso em 20 de setembro de 2020.

45 MAGGI, Bruno Oliveira. Nova proposta de classificação do dano no direito civil. Revista de Direito Privado, São Paulo, v.8, n.32, 2007, p.32-54.

${ }^{46} \mathrm{BENUCCI}$, Eduardo Bonasi. La responsabilidade civil. Tradução de Juan V. Fuentes Lojo y José Peré Raluy. Barcelona: Jose Maria Bosch, 1958, p.100.

${ }^{47}$ MORAES, Maria Celina Bodin de. Danos à pessoa humana: uma leitura civil-constitucional dos danos

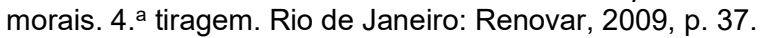

48 MARTINS-COSTA, Judith Hofmeister. Os danos à pessoa no direito brasileiro e a natureza da sua reparação. In: MARTINS-COSTA, Judith Hofmeister (Org.). A reconstrução do direito privado: reflexos dos princípios, diretrizes e direitos fundamentais constitucionais no direito privado. São Paulo: RT, 2002, p. 444.

${ }^{49}$ BRASIL. Superior Tribunal de Justiça. Recurso Especial n. ${ }^{\circ}$ 1.758.799/MG (2017/0006521-9). Relatora Ministra Nancy Andrighi. Terceira Turma. Julgado em 12/11/2019, DJe 19/11/2019. Disponível em: https://ww2.stj.jus.br/websecstj/cgi/revista/REJ.cgi/lTA?seq=1888267\&tipo=0\&nreg=201700065219\&SeqCg rmaSessao=\&CodOrgaoJgdr=\&dt=20191119\&formato=PDF\&salvar=false. Acesso em: 17 dez. 2019.

50 BRASIL. Superior Tribunal de Justiça. Recurso Especial n. ${ }^{\circ}$ 1.758.799/MG (2017/0006521-9). Relatora Ministra Nancy Andrighi. Terceira Turma. Julgado em 12/11/2019, DJe 19/11/2019. Disponível em: https://ww2.stj.jus.br/websecstj/cgi/revista/REJ.cgi/lTA?seq=1888267\&tipo=0\&nreg=201700065219\&SeqCg rmaSessao=\&CodOrgaoJgdr=\&dt=20191119\&formato=PDF\&salvar=false. Acesso em: 17 dez. 2019. 
É sabido que os dados são denominados como o novo petróleo ${ }^{51}$, portanto, será que essa quantia efetivamente tem o caráter de desestímulo, "[...] de modo a conscientizar o ofensor de que não deve persistir no comportamento lesivo"52?

A presente pergunta tem sua relevância porque, caso o valor seja ínfimo, pode ocorrer exatamente o contrário. São os denominados "ilícitos lucrativos" ${ }^{33}$, quando o valor da condenação é tão ínfimo que, ao calcular o lucro obtido pela conduta (ainda que indevida) e a reparação a ser paga (em caso de condenação), o resultado é de que, economicamente, vale a pena lesar, tal como ocorreu no paradigmático caso Ford Pinto ${ }^{54}$.

Este caso ilustra bem a análise do custo-benefício entre o lucro possível e o valor de eventual condenação judicial. É que, não obstante a Ford tivesse conhecimento de que havia um defeito de fabricação no automóvel por ela fabricado, o qual poderia causar danos aos compradores do automóvel ou até mesmo a sua morte, ela optou pela sua comercialização, pois o conserto custaria mais caro do que as possíveis reparações. Em razão deste cálculo, houve a sua condenação em danos punitivos ${ }^{55}$.

No ordenamento jurídico brasileiro, os danos punitivos aplicados no caso Ford Pinto para punir o cálculo do custo-benefício e impedir que tal ação se repetisse não podem ser aplicados, em tese, eis que esbarrariam, a princípio, no disposto no art. 944 do Código Civili ${ }^{56}$, que determina que o valor da reparação seja equivalente à extensão do dano.

${ }^{51}$ FRAZÃO, Ana. Fundamentos da proteção dos dados pessoais - Noções introdutórias para a compreensão da importância da Lei Geral da Proteção de Dados. In: FRAZÃO, Ana; TEPEDINO, Gustavo; OLIVA, Milena Donato (Coord.). Lei Geral de Proteção de Dados Pessoais e suas repercussões no Direito Brasileiro. São Paulo: Thomson Reuters Brasil, 2019, p. 24.

52 MORAES, Maria Celina Bodin de. Punitive damages em sistemas civilistas: problemas e perspectivas. Revista Trimestral de Direito Civil. v.5, n.18, p.51, abr.jjun. 2004.

${ }^{53}$ ROSENVALD, Nelson. A responsabilidade civil pelo ilícito lucrativo: o disgorgement e a indenização restitutória. Salvador: Juspodivm, 2019.

54 LEGGETT, Christopher. The Ford Pinto Case: the valuation on life as it applies to the negligence efficiency argument. Law \& valuation. Professor Palmiter. Spring, 1999. Disponível em: http://users.wfu.edu/palmitar/Law\&Valuation/Papers/1999/Leggett-pinto.html. Acesso em: 13 ago. 2020. 55 "O Ford Pinto foi um modelo de automóvel desenvolvido pela Ford, que após a fabricação foi submetido a testes de direção, quando constatando que havia a probabilidade de rompimento do tanque de combustível em caso de colisão traseira do automóvel, ocasionando a combustão e possibilidade de acarretar ferimentos aos passageiros. Todavia, diante do custo por carro para adequar a engenharia do modelo (seria de US\$ 11,00 - onze dólares - por carro, um total de US\$137 milhões - cento e trinta e sete milhões de dólares) e o valor das possíveis indenizações (US\$ 49.5 - quarenta e nove milhões e quinhentos mil dólares), a Ford preferiu comercializar o veículo sem realizar os ajustes necessários. E o modelo Pinto foi comercializado com os riscos para os seus passageiros que eram de amplo conhecimento da Ford, no ano de 1968. Mas, em maio de 1972, Lily Gray e o seu filho de 13 (treze) anos de idade à época, Richard Grimshaw, estavam viajando em um Ford Pinto, quando foram atingidos na traseira do veículo e a colisão acarretou o incêndio do carro, vindo a mãe a falecer e a criança a sofrer lesões gravíssimas. Com a comprovação de que a empresa realizou estudos do custo/benefício, através de documentos nos quais estavam descritos os custos indenizatórios (incluindo medicamentos, tempo de internação, gastos com advogado, despesas funeral, dentre outras), a empresa foi condenada ao pagamento de danos materiais e danos punitivos (inicialmente em US\$125.000.000,00 - cento e vinte e cinco milhões de dólares -, reduzidos para US\$ 3.500.000,00 três milhões e quinhentos mil dólares)." GONDIM, Glenda Gonçalves. Responsabilidade civil sem dano: da lógica reparatória à lógica inibitória. Tese de doutorado apresentada no Programa de Pós Graduação da Universidade Federal do Paraná. https://acervodigital.ufpr.br/bitstream/handle/1884/40367/R\%20-\%20T\%20-\%20GLENDA\%20GONCALVES \%20GONDIM.pdf?sequence=2\&isAllowed=y, p. 244. Acesso em: 20 jul. 2020.

56 Art. 944. A indenização mede-se pela extensão do dano. (BRASIL, Lei n. ${ }^{\circ} 10.406$, de 10 de janeiro de 2002. Código Civil. Disponível em: http://www.planalto.gov.br/ccivil_03/leis/2002/l10406.htm. Acesso em: 03 maio 2020.) 
Há, ainda, uma agravante para o caso dos danos decorrentes dos dados pessoais, eis que há dificuldade em se avaliar o próprio dano. Isto porque, ao se falar sobre dados, é difícil precisar o seu valor, apesar da especulação existente. Em verdade, o que é possível é basear-se em estimativas, tal como ocorreu com a avaliação dos dados dos usuários do WhatsApp, que, quando da venda do aplicativo para o Facebook, foi estimado que, para obter lucro, deveria ser cobrado o valor de U\$12,00 (doze dólares), anualmente, por usuário ${ }^{57}$.

Com este parâmetro e outros que possam surgir, será possível ao Judiciário apurar, ainda que imprecisamente, mas o mais próximo possível, o lucro obtido e, por consequência, o valor do dano de forma que sirva não apenas como compensação, mas, também, desestímulo.

Esta seria uma das possíveis respostas para uma adequada reparação. Todavia, a avaliação do dano individual também esbarraria nos critérios comuns de apreciação do dano extrapatrimonial/moral, não apenas quanto à extensão do dano, mas relativamente às capacidades econômicas de vítima e ofensor, não obstante as críticas cabíveis a estes critérios $^{58}$.

Por isso e, tendo em vista que se trata de danos que atingem uma coletividade, que não necessariamente constituir-se-ão em interesse público para a reparação do dano, o dano coletivo torna-se o mais viável. Alternativamente, a categoria do dano social, desenvolvida por Antônio Junqueira de Azevedo, merece menção, uma vez que este tipo de dano, pleiteado através dos critérios processuais da tutela coletiva, possui como embasamento o objetivo de desestímulo "[...] tanto para o agente quanto para outros que fiquem tentados a repetir o mesmo ato lesivo"59.

Os valores obtidos com as reparações poderiam ser revertidos aos fundos de defesas de direitos difusos ${ }^{60}$, com direcionamento pelo Ministério da Justiça a políticas públicas relacionadas ao direito a dados, que devem ser desenvolvidas pela Autoridade Nacional de Proteção de Dados ${ }^{61}$.

Com este dano, não individual, é possível pensar em responsabilização e reparação adequadas que não apenas reparem a lesão, mas também possam atuar como forma de prevenção.

\section{CONSIDERAÇÕES FINAIS}

A sociedade atual tem como fonte principal a informação, cuja matéria-prima são os dados, inclusive pessoais. Estes elementos são utilizados para diversos fins e, por isso, há

${ }^{57}$ BIONI, Bruno Ricardo. Proteção de dados pessoais: a função e os limites do consentimento. Rio de Janeiro: Forense, 2019, p. 33-35.

${ }^{58}$ SCHREIBER, Anderson. Arbitramento do dano moral no novo Código Civil. Revista Trimestral de Direito Civil, Rio de Janeiro, v.12, 2002, p.3-24.

${ }^{59}$ AZEVEDO, Antonio Junqueira de. Por uma nova categoria de dano na responsabilidade civil: o dano social. In: AZEVEDO, Antonio Junqueira de. Novos estudos e pareceres de direito privado. São Paulo: Saraiva, 2009. p.377-384, p. 380.

60 BRASIL, Lei $n .^{\circ} 9.008$, de 21 de março de 1995. Disponível em: http://www.planalto.gov.br/ ccivil_03/leis/19008.htm. Acesso em: 03 maio 2020.

61 "Art. 55-J (...) VI - promover na população o conhecimento das normas e das políticas públicas sobre proteção de dados pessoais e das medidas de segurança;" (BRASIL, Lei n. ${ }^{\circ} 13.709$, de 14 de agosto de 2018. Lei Geral de Proteção de Dados. Disponível em: http://www.planalto.gov.br/ccivil_03/_ato20152018/2018/lei/L13709.htm. Acesso em: 20 set. 2020.) 
necessidade de proteção pontual e efetiva do que se denomina direito sobre a proteção dos dados pessoais.

A proteção estudada no presente trabalho foi a responsabilidade civil, disposta na legislação brasileira (Lei n. ${ }^{\circ} 13.709$, de 14 de agosto de 2018), que trata do tema. Apesar de algumas controvérsias apresentadas, tal como o disciplinamento de certas ações que devem ser entendidas como situações exemplificativas, bem como pela omissão sobre a avaliação do ato antijurídico, se de forma subjetiva ou objetiva, a possibilidade de responsabilização daquele que age contrariamente ao direito, a proteção sobre os dados pessoais resta consagrada na legislação e jurisprudência.

Assim, a preocupação que surge é de que a legislação permanece enraizada em problemas já existentes no ordenamento jurídico. Eis que, ao se verificar a responsabilidade, surge o questionamento sobre como reparar. As regras existentes para a reparação, especialmente quando o dano decorrente da ofensa é extrapatrimonial, podem estimular condutas antijurídicas ao invés de exercer a função de desestímulo. É que é difícil mensurar o valor efetivo dos dados pessoais e, também, o critério da capacidade econômica da vítima e do ofensor, o que pode impedir a justa reparação.

Neste momento, a melhor resposta para essa inquietação aparenta ser a possibilidade de demandas albergadas pela tutela coletiva, tal como a categoria de dano formulada pelo Professor Antônio Junqueira de Azevedo, denominada como dano social. Nestes casos, entendese possível reparar e desestimular o ofensor ao mesmo tempo.

\section{REFERÊNCIAS}

AZEVEDO, Antonio Junqueira de. Por uma nova categoria de dano na responsabilidade civil: o dano social. In: AZEVEDO, Antonio Junqueira de. Novos estudos e pareceres de direito privado. São Paulo: Saraiva, 2009. p.377-384.

BENUCCI, Eduardo Bonasi. La responsabilidade civil. Tradução de Juan V. Fuentes Lojo y José Peré Raluy. Barcelona: Jose Maria Bosch, 1958.

BIONI, Bruno Ricardo. Proteção de dados pessoais: a função e os limites do consentimento. Rio de Janeiro: Forense, 2019.

BRASIL, Lei n. ${ }^{\circ}$ 9.008, de 21 de março de 1995. Disponível em: http://www.planalto.gov.br/ccivil_03/leis/l9008.htm. Acesso em: 03 maio 2020.

BRASIL, Lei n. ${ }^{\circ} 8.078$, de 11 de setembro de 1990. Código de Defesa do Consumidor. Disponível em http://www.planalto.gov.br/ccivil_03/leis//8078compilado.htm. Acesso em 03 de maio de 2020.

BRASIL, Lei n. ${ }^{\circ} 10.406$, de 10 de janeiro de 2002. Código Civil. Disponível em: http://www.planalto.gov.br/ccivil_03/leis/2002/l10406.htm. Acesso em: 03 maio 2020.

BRASIL, Lei n. ${ }^{\circ} 13.709$, de 14 de agosto de 2018. Lei Geral de Proteção de Dados. Disponível em: http://www.planalto.gov.br/ccivil_03/_ato2015-2018/2018/lei/L13709.htm. Acesso em: 20 set. 2020.

BRASIL. Proposta de Emenda Constitucional n. ${ }^{\circ}$ 17/2019. Disponível em https://www25.senado.leg.br/web/atividade/materias/-/materia/135594. Acesso em: 12 set. 2020. 
BRASIL. Superior Tribunal de Justiça. Recurso Especial $n .^{\circ}$ 1.758.799/MG (2017/0006521-9). Relatora Ministra Nancy Andrighi. Terceira Turma. Julgado em 12/11/2019, DJe 19/11/2019. Disponível

em:

https://ww2.stj.jus.br/websecstj/cgi/revista/REJ.cgi//TA?seq=1888267\&tipo=0\&nreg=2017000652

$19 \&$ SeqCgrmaSessao $=\&$ CodOrgaoJgdr $=\& d t=20191119 \&$ formato=PDF\&salvar=false. Acesso em: 17 dez. 2019.

BRASIL. Superior Tribunal de Justiça. Súmula 479. Disponível em https://scon.stj.jus.br/SCON/sumanot/toc.jsp. Acesso em: 29 ago. 2020.

CASTELLS, Manuel. A sociedade em rede. A era da informação: economia, sociedade e cultura. Tradução de Roneide Venancio Majer. 20. ed., rev. e ampl. v. 1. São Paulo: Paz e Terra, 2019.

DONEDA, Danilo. A proteção dos dados pessoais como um direito fundamental. Espaço Jurídico. Joaçaba, v. 12, n. 2. Jul/dez. 2011.

DONEDA, Danilo. Da privacidade à proteção de dados pessoais. Rio de Janeiro: Renovar, 2006.

FRAZÃO, Ana. Fundamentos da proteção dos dados pessoais - Noções introdutórias para a compreensão da importância da Lei Geral da Proteção de Dados. In: FRAZÃO, Ana; TEPEDINO, Gustavo; OLIVA, Milena Donato (Coord.). Lei Geral de Proteção de Dados Pessoais e suas repercussões no Direito Brasileiro. São Paulo: Thomson Reuters Brasil, 2019, p. 23-52.

FRAZÃO, Ana. Objetivos e alcance da Lei Geral de Proteção de Dados In: FRAZÃO, Ana; TEPEDINO, Gustavo; OLIVA, Milena Donato (Coord.). Lei Geral de Proteção de Dados Pessoais e suas repercussões no Direito Brasileiro. São Paulo: Thomson Reuters Brasil, 2019, p. 99-129.

GONDIM, Glenda Gonçalves. Responsabilidade civil sem dano: da lógica reparatória à lógica inibitória. Tese de doutorado apresentada no Programa de Pós Graduação da Universidade Federal do Paraná. Disponível em https://acervodigital.ufpr.br/bitstream/handle/1884/40367/R\%20-\%20T\%20-

\%20GLENDA\%20GONCALVES\%20GONDIM.pdf?sequence=2\&isAllowed=y. Acesso em: 20 jul. 2020.

GUEDES, Gisela Sampaio da Cruz. MEIRELLES, Rose Melo Vencelau. Término do tratamento de dados. In: FRAZÃO, Ana; TEPEDINO, Gustavo; OLIVA, Milena Donato (Coord.). Lei Geral de Proteção de Dados Pessoais e suas repercussões no Direito Brasileiro. São Paulo: Thomson Reuters Brasil, 2019, p. 219-241.

LEGGETT, Christopher. The Ford Pinto Case: the valuation on life as it applies to the negligence efficiency argument. Law \& valuation. Professor Palmiter. Spring, 1999. Disponível em: http://users.wfu.edu/palmitar/Law\&Valuation/Papers/1999/Leggett-pinto.html. Acesso em: 13 ago. 2020.

LUÑO, Antonio E. Pérez. Informática y libertad. Comentario ao articulo 18.4 de la Constitucion. Revista de Estudios Politicos, n. 24, nov. 1981.

MARTINS-COSTA, Judith Hofmeister. Os danos à pessoa no direito brasileiro e a natureza da sua reparação. In: MARTINS-COSTA, Judith Hofmeister (Org.). A reconstrução do direito privado: reflexos dos princípios, diretrizes e direitos fundamentais constitucionais no direito privado. São Paulo: RT, 2002. p.408-446.

MAGGI, Bruno Oliveira. Nova proposta de classificação do dano no direito civil. Revista de Direito Privado, São Paulo, v.8, n.32, 2007, p.32-54.

MAIA, Roberta Mauro Medina. A titularidade de dados pessoais prevista no art. 17 da LGPD: direito real ou pessoal? In: FRAZÃO, Ana; TEPEDINO, Gustavo; OLIVA, Milena Donato (Coord.). Lei Geral de Proteção de Dados Pessoais e suas repercussões no Direito Brasileiro. São Paulo: Thomson Reuters Brasil, 2019, p. 131-156. 
MIRAGEM, Bruno Nunes Barbosa. Direito civil: responsabilidade civil. São Paulo: Saraiva, 2015.

MORAES, Maria Celina Bodin de. Danos à pessoa humana: uma leitura civil-constitucional dos danos morais. 4. ${ }^{a}$ tiragem. Rio de Janeiro: Renovar, 2009.

MORAES, Maria Celina Bodin de. Punitive damages em sistemas civilistas: problemas e perspectivas. Revista Trimestral de Direito Civil. v.5, n.18, p.51, abr./jun. 2004.

MORAES, Maria Celina Bodin de. QUEIROZ, João Quinelato de. Autodeterminação informativa e responsabilização proativa: novos instrumentos de tutela da pessoa humana na LGPD. Proteção de Dados Pessoais: avanço tecnológico. Cadernos Adenauer. Ano XX (2019), n. ${ }^{\circ} 3$. Rio de Janeiro: Fundação Konrad Adenauer, outubro 2019, p. 113-135.

MULHOLLAND, Caitlin. A LGPD e o fundamento da responsabilidade civil dos agentes de tratamento de dados pessoais: culpa ou risco? Migalhas. Migalhas de responsabilidade civil. Disponível em https://www.migalhas.com.br/coluna/migalhas-de-responsabilidade-civil/329909/aIgpd-e-o-fundamento-da-responsabilidade-civil-dos-agentes-de-tratamento-de-dados-pessoais-culpa-ou-risco. Acesso em 20 de julho de 2020.

PARANÁ. Tribunal de Justiça. Autos $n .^{\circ}$ 0000007-20.2020.8.16.0147. Disponível em https://projudi.tjpr.jus.br/projudi/. Acesso em 20 de setembro de 2020.

PINHEIRO, Patrícia Peck. Direito digital. 6. ed., rev., atual. e ampl. São Paulo: Saraiva, 2016.

RODOTÀ, Stefano. A vida na sociedade de vigilância: a privacidade hoje. Tradução de Danilo Doneda e Luciana Cabral Doneda. Organização, seleção e apresentação de Maria Celina Bodin de Moraes. Rio de Janeiro: Renovar, 2008.

ROSENVALD, Nelson. A responsabilidade civil pelo ilícito lucrativo: o disgorgement e a indenização restitutória. Salvador: Juspodivm, 2019.

SCHREIBER, Anderson. Arbitramento do dano moral no novo Código Civil. Revista Trimestral de Direito Civil, Rio de Janeiro, v.12, 2002, p.3-24.

SCHREIBER, Anderson. Novos paradigmas da responsabilidade civil: da erosão dos filtros da reparação à diluição dos danos. São Paulo: Atlas, 2007.

SECRETARIA GERAL IBERO AMERICANA. RIPD 2020. Rede Ibero Americana de Proteção de Dados. Padrões de Proteção de Dados dos Estados Ibero-Americanos. Disponível em https://www.argentina.gob.ar/sites/default/files/pt_br_estandares_iberoamericanos_de_proteccio n_de_datos.pdf. Acesso em: 03 mar. 2020.

TEPEDINO, Gustavo. TEFFÉ, Chiara Spadaccini. Consentimento e proteção de dados pessoais na LGPD. In: FRAZÃO, Ana; TEPEDINO, Gustavo; OLIVA, Milena Donato (Coord.). Lei Geral de Proteção de Dados Pessoais e suas repercussões no Direito Brasileiro. São Paulo: Thomson Reuters Brasil, 2019, p. 287-322.

UNIÃO EUROPEIA. Regulamento n. ${ }^{\circ} 2016 / 679$ do Parlamento Europeu e do Conselho de 27 de abril de 2016. Regulamento Geral de Proteção de Dados. Disponível em https://eurlex.europa.eu/legal-content/PT/TXT/HTML/?uri=CELEX:32016R0679\&from=EN. Acesso em: 03 maio 2020.

UNIÃO EUROPEIA. Carta dos Direitos Fundamentais da União Europeia (CDFUE). 07 de dezembro de 2000.2 Disponível em https://www.cnpd.pt/home/legis/internacional/CARTAFUNDAMENTAL.pdf. Acesso em: 10 ago. 2020.

VENTURI, Thaís Goveia Pascoaloto. Responsabilidade civil preventiva: a proteção contra a 
violação dos direitos e a tutela inibitória material. São Paulo: Malheiros, 2014.

Recebido: 30.09 .2020

Aprovado: 01.12.2020

Como citar: GONDIM, Glenda Gonçalves. A responsabilidade civil no uso indevido dos dados pessoais. Revista IBERC, Belo Horizonte, v. 4, n. 1, p. 19-34, jan./abr. 2021. 